This item was submitted to Loughborough's Research Repository by the author.

Items in Figshare are protected by copyright, with all rights reserved, unless otherwise indicated.

\title{
Modelling the foetus for pregnant occupant safety
}

PLEASE CITE THE PUBLISHED VERSION

http://dx.doi.org/10.1177/1464419312452478

PUBLISHER

Sage /@ IMechE

VERSION

AM (Accepted Manuscript)

LICENCE

CC BY-NC-ND 4.0

REPOSITORY RECORD

Acar, B. Serpil, and David W. van Lopik. 2019. "Modelling the Foetus for Pregnant Occupant Safety". figshare. https://hdl.handle.net/2134/14951. 


\title{
Modelling the Fetus for Pregnant Occupant Safety \\ B Serpil Acar* and D van Lopik ${ }^{+}$ \\ Design School, Loughborough University, UK
}

\begin{abstract}
Annual fetus mortality rates due to road traffic accidents are much higher than the infant mortality rates in motor vehicle crashes. The goal of this study is to generate a computational model of the unborn occupant (fetus) for crash protection research. The multibody fetus model is accommodated in the Finite element uterus model of 'Expecting', the computational pregnant occupant model which tackles the complexity of a pregnant women's anatomy and incorporates pregnant female anthropometry.

In particular, 38 weeks gestation level is focused upon since at this stage of pregnancy the fetus is at greatest risk during a crash due to the size increase of the abdomen resulting in a close proximity to the vehicle steering wheel and awkward routing of the seatbelt. This article explains in detail all stages of modelling the unborn occupant and the links to its environment, the uterus with a placenta and the computational female model.
\end{abstract}

* Corresponding Author

+ now at Atkins Aviation and Defense Systems 


\section{INTRODUCTION}

It has been shown in the literature that motor vehicle collisions are the leading cause of accidental fetal death [1]. In the UK alone there are approximately 750,000 pregnant women each year all of which are likely to be vehicle drivers or passengers during some or all stages of their pregnancy [2-4]. It has been estimated that around 3400 women in the second half of pregnancy are involved in car crashes annually [5]. Fetus mortality rates due to accidents are much higher than the infant mortality rates in motor vehicle crashes and the number of children die because of the bicycle accidents [2].

The risks to the fetus in the case of an automobile impact have been described in medical studies as being; placental abruption [6], [7], maternal death [8], direct fetal injury [9], feto-maternal transfusion [10], onset of labour and preterm delivery [11].

The safety of pregnant women as car occupants may be compromised due to the size and shape changes that occur during pregnancy as well as due to the added complexity of having an occupant within an occupant. Early investigations using pregnant baboons and monkeys concluded that the standard 3-pt seatbelt system provided better protection to both mother and fetus compared to just the lap portion of the belt [12]. In the mid 90's a pregnancy insert for the Hybrid III small female was developed in [13] to further explore the affect of loading of vehicle safety systems on the approximately 28week pregnant occupant. This physical model included a urethane fetus which fitted inside a urethane casing that fitted inside a urethane uterus. The model had many limitations such as a non-anthropometric shape, unrealistically high stiffness and attached weights which would affect overall ATD kinematics. A 
second-generation physical model of pregnancy insert was developed [14]. The model has more realistic anthropometry however it has neither a placenta nor fetus instead the uterus is filled with water. A computational model to represent a pregnant driver was also developed [15], using MADYMO, combining a FE model of a liquid-filled uterus, without fetus, within an existing $5^{\text {th }}$ percentile female occupant model available in the MADYMO package.

The significant mass of the considerably solid fetus during the later stages of pregnancy almost fills the entire volume of uterus but is reasonably free to move during an impact, only constrained by the boundaries of the uterus. The fetus has therefore the potential to affect the entire dynamic response to impact. Hence the magnitude and location of the forces exerted by the solid fetus and the consequent stresses and strains would be significantly different than those exerted by the fluid alone. Hence the lack of any representation of a fetus in recent models, both physical and computational, warrants further investigation in this area.

The focus of this paper is on the generation of a detailed computational representation, multibody model of the unborn occupant, the fetus, as part of the computational model of pregnant women 'Expecting'.

\section{FETUS AND UTERUS ANATOMY}

Figure 1 shows the general anatomy of fetus and uterus near term, as with $95 \%$ of all pregnancies the fetus assumes an upside-down position with its head downwards nestled within the confines of the pelvis bones. The fetus is surrounded by amniotic fluid; this fluid physically cushions the embryo as it 
develops and permits free movement of the fetus. At term the volume of amniotic fluid relative to that of the fetus is at its lowest.

The placenta, a large vascular organ covering approximately a quarter of the inner surface of the uterus, is generally, in around $80 \%$ of pregnancies, located at the fundus (top) of the uterus. The placenta has a flattened discoidal mass with a roughly circular shape. It has an average weight of around $470 \mathrm{~g}$ (range $200-800 \mathrm{~g}$ ), an average diameter of $185 \mathrm{~mm}$ (range $150-200 \mathrm{~mm}$ ) and an average thickness of $23 \mathrm{~mm}$ at its centre (range $10-40 \mathrm{~mm}$ ). The placenta attaches to the internal surface of the uterus via small finger-like protrusions from the surface of the placenta known as microvilli, as well as connecting the two structures; this utero-placental interface (UPI) facilitates nutrient transportation to the fetus [16], [17].

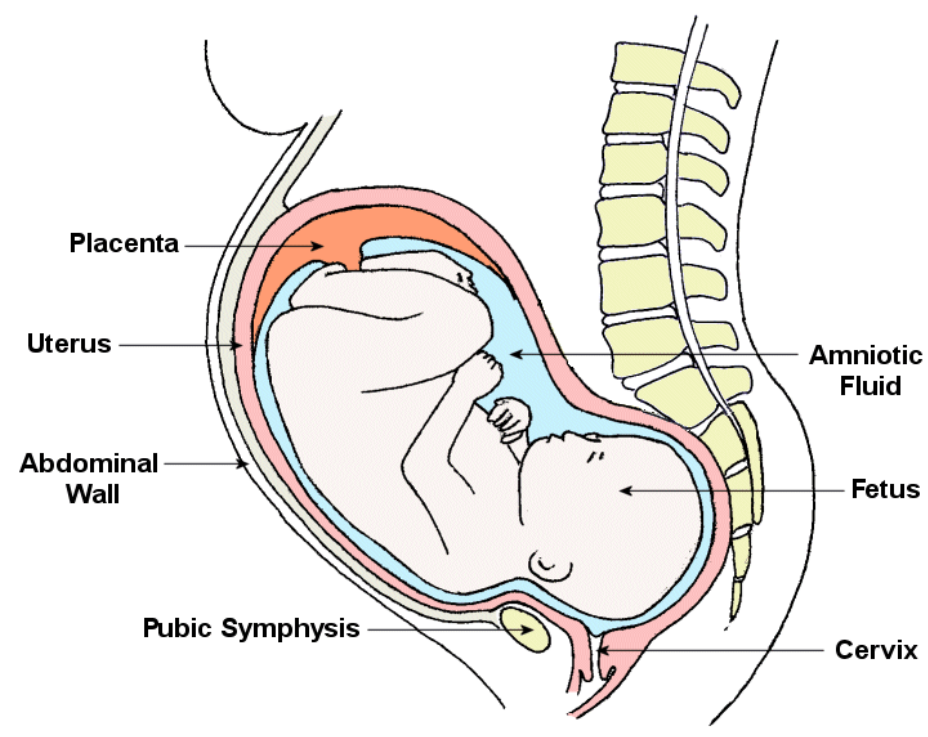

Fig 1 Anatomy of the pregnant abdomen.

The uterus grows dramatically during pregnancy increases in weight significantly and it expands out of the pelvic basin displacing other abdominal organs upward with the uterine fundus reaching the level of the xiphisternum by 
the $36^{\text {th }}$ week of gestation. At this stage the uterine wall thickness is approximately $10 \mathrm{~mm}$. The uterus is attached at the cervix to the pelvis and sacrum via ligaments but is otherwise unattached in the abdominal cavity; from around the $16^{\text {th }}$ week onwards the uterus makes contact with the anterior abdominal wall and the lumbar and sacral spines.

\section{MODELLING THE UNBORN OCCUPANT: FETUS}

At later stages of pregnancy, beyond 30 weeks, as the abdominal size increases, its proximity to the steering wheel during driving gets closer. Also in the later stages of pregnancy the amount of amniotic fluid surrounding the fetus, which is thought to offer some degree of protection, is at a minimum and the fetus occupies the majority of the uterine volume. It is therefore decided in this study to model a 38-week fetus and uterus, a very close to term, in order to create a model for the investigations where the pregnant women are most concerned [18].

The multibody model of the fetus is composed of 15 rigid bodies representing the different body regions of the fetus interconnected by kinematic joints. Each rigid body is defined by its mass, moments of inertia and its centre of gravity position. The geometric surface of the various body segments are represented by ellipsoids with dimensions estimated from fetal biometric measurements or scaled from anthropometric data of newborns found in the literature. Ellipsoids are positioned with respect to their parent rigid body. Kinematic joints connect the rigid bodies. Mass and moment of inertia properties of the segments along with the characteristics of the joints connecting them have been scaled from existing multibody models of infants. The details of geometry, mass and inertial 
properties, joint properties and the contacts are given in this section.

\subsection{Geometry}

The anatomy of the $38^{\text {th }}$ week fetus is represented by hyper ellipsoids, which require the specification of the lengths of the three semi-axes as well as the position of the centre and ellipsoid orientation relative to their parent rigid body. The dimensions of the various segments were mostly derived from a combination of fetal biometric measurements and scaling of anthropometric measurements from newborns. When direct fetal biometric measurements or newborn data is not available at all, existing infant and child models available in the MADYMO dummy database are scaled and used.

Head: Ultrasound measurements of the biparietal diameter (BPD) and occipitofrontal diameter (OFD) (measured from the outer borders of the skull) were used to define the semi-axes or the head [19-20]. The mean BPD (96mm) and OFD $(115 \mathrm{~mm})$ measurements for a $38^{\text {th }}$ week old fetus correlate well with the recorded mean head breadth $(95 \mathrm{~mm})$ and head length $(120 \mathrm{~mm})$ respectively of newborns [21].

Limbs: Ultrasound measurements of the fetal long-bones as presented in [22] were used to derive the semi axes of the leg and arm segments. For the femur or upper leg segment the measured bone length for a $38^{\text {th }}$ week fetus was $76 \mathrm{~mm}$, this length defines the distance between the hip and knee joint in the model, the primary axes of the ellipsoid used to represent the segment is slightly longer to allow overlapping of the segments. Similarly for the tibia, or lower leg, the measured length of $66 \mathrm{~mm}$ defines the distance between the knee joint and ankle joint. Foot length was obtained from [23]. For the arms measured bone lengths of $66 \mathrm{~mm}$ and $61 \mathrm{~mm}$ for the humerus and ulna 
respectively have been taken from [22]. For the upper arm the humerus length defines the distance between the shoulder and elbow joints. No body is defined to represent the hands in the model so the ellipsoid used to represent the lower arms incorporates the added length of the hands.

Pelvis Abdomen and Torso: The measured abdominal circumference of $339 \mathrm{~mm}$ for $\mathrm{a} 38^{\text {th }}$ week old fetus measured and recorded by [19] was used to obtain a scaling factor for other trunk measurements where direct fetal measurements are not available. The mean waist circumference of $1630-3$ month old new-borns were recorded in [24] as $356.1 \mathrm{~mm}$. This gives a scaling factor of 0.95 . This scaling factor was used to determine the ellipsoid dimensions of the pelvis and abdomen.

Table 1: Inertial and geometric data used for the rigid bodies of the fetal model.

\begin{tabular}{|c|c|c|c|c|c|c|c|c|c|c|c|}
\hline \multirow[b]{2}{*}{ Name } & \multirow{2}{*}{$\begin{array}{c}\text { Parent } \\
\text { Body }\end{array}$} & \multirow[b]{2}{*}{ Mass } & \multicolumn{3}{|c|}{ Moments of Inertia } & \multicolumn{3}{|c|}{$\begin{array}{c}\text { Origin of local } \\
\text { coordinate system w.r.t } \\
\text { parent coordinate system }\end{array}$} & \multicolumn{3}{|c|}{ Position of CoG } \\
\hline & & & $\mathrm{I}_{\mathrm{xx}}$ & $\mathrm{I}_{\mathrm{yy}}$ & $\mathrm{I}_{\mathrm{zz}}$ & $\mathrm{S}_{\mathrm{x}}$ & $\mathrm{S}_{\mathrm{y}}$ & $\mathrm{S}_{\mathrm{z}}$ & $g_{x}$ & $\mathrm{~g}_{\mathrm{y}}$ & $g_{z}$ \\
\hline & & $\mathrm{kg}$ & & $\mathrm{kg} \cdot \mathrm{cm}^{2}$ & & & $\mathrm{~mm}$ & & & $\mathrm{~mm}$ & \\
\hline P1 Pelvis & Ref & 0.42 & 19.0 & 14.0 & 17.0 & 0.0 & 0.0 & 0.0 & 2.6 & 0.0 & 5.6 \\
\hline A1 Abdomen & $\mathrm{P} 1$ & 0.12 & 10.0 & 10.0 & 10.0 & -15.4 & 0.0 & 30.0 & 14.0 & 0.0 & 23.0 \\
\hline T1 Thorax & A1 & 0.62 & 54.0 & 31.0 & 32.0 & 0.0 & 0.0 & 55.0 & 0.1 & 0.0 & 43.0 \\
\hline N1 Neck & $\mathrm{T} 1$ & 0.08 & 10.0 & 10.0 & 1.0 & 0.0 & 0.0 & 57.0 & 0.0 & 0.0 & 27.0 \\
\hline H1 Head & N1 & 1.02 & 20.1 & 21.6 & 25 & 0.0 & 0.0 & 54.0 & 6.0 & 0.0 & 30.0 \\
\hline HL1 HumerusL & $\mathrm{T} 1$ & 0.11 & 5.0 & 5.0 & 1.0 & 5.0 & 43.0 & 63.0 & -2.7 & -1.9 & -26.4 \\
\hline HR1 HumerusR & $\mathrm{T} 1$ & 0.11 & 5.0 & 5.0 & 1.0 & 5.0 & -43.0 & 63.0 & -2.7 & 1.9 & -26.4 \\
\hline UL1 UlnaL & HL1 & 0.062 & 3.0 & 3.0 & 1.0 & 0.0 & 0.0 & -65.0 & -3.8 & 1.5 & -41.7 \\
\hline UR1 UlnaR & HR1 & 0.062 & 3.0 & 3.0 & 1.0 & 0.0 & 0.0 & -65.0 & -3.8 & 1.5 & -41.7 \\
\hline FL1 FemurL & $\mathrm{P} 1$ & 0.18 & 3.0 & 8.9 & 8.9 & 0.0 & 35.0 & 0.0 & 45.0 & -2.8 & -1.7 \\
\hline FR1 FemurR & $\mathrm{P} 1$ & 0.18 & 3.0 & 8.9 & 8.9 & 0.0 & -35.0 & 0.0 & 45.0 & 2.8 & -1.7 \\
\hline TL1 TibiaL & FL1 & 0.13 & 10.0 & 10.0 & 1.0 & 0.0 & 0.0 & -76.0 & -2.0 & -4.0 & -4.5 \\
\hline TR1 TibiaR & FR1 & 0.13 & 10.0 & 10.0 & 1.0 & 0.0 & 0.0 & -76.0 & -2.0 & 4.0 & -4.5 \\
\hline FL1 FootL & TL1 & 0.04 & 1.0 & 1.0 & 1.0 & 0.0 & 0.0 & -66.0 & 17.0 & 0.0 & -7.0 \\
\hline FR1 FootR & TR1 & 0.04 & 1.0 & 1.0 & 1.0 & 0.0 & 0.0 & -66.0 & 17.0 & 0.0 & -7.0 \\
\hline
\end{tabular}

\subsection{Mass and Inertial Properties}

An estimated fetal weight of $3.3 \mathrm{~kg}$, from [25] based on the biparietal diameter and abdominal circumference used in the model, was selected. This corresponds to the mean fetal weight (male and female averaged) of $3.28 \mathrm{~kg}$ for 
a $38^{\text {th }}$ week old fetus. Segment weights were scaled from the TNO 9-month-old child dummy using the major dimensions of each segment to determine respective scaling factors. The mass of each segment is shown in Table 1.

The inertial properties of the fetus are lumped into the rigid bodies. The position of the centre of gravity of a particular body is given with respect to the local coordinate system of that body, $g_{x}, g_{y}, g_{z}$ (Table 1). The positions of the centre of gravity for each rigid body were obtained from the TNO 9 month old child dummy, for each body segment a scaling factor was obtained from the respective ellipsoid surface in $x, y$ and $z$ directions and used to scale the CoG position for each axis. Table 1 also lists the CoG position for each of the rigid bodies in the fetus model.

The principle moments of inertia of each body are defined with respect to the centre of gravity and parallel to the local coordinate system. Non-linear regression equations for the estimation of segmental inertia properties of the human body is published in [26]. The equations were derived from anthropometric measurements and segmental moments of inertia taken from the study reported in [27]. The calculated moments of inertia of the various body segments of the fetus are given in Table 1. 

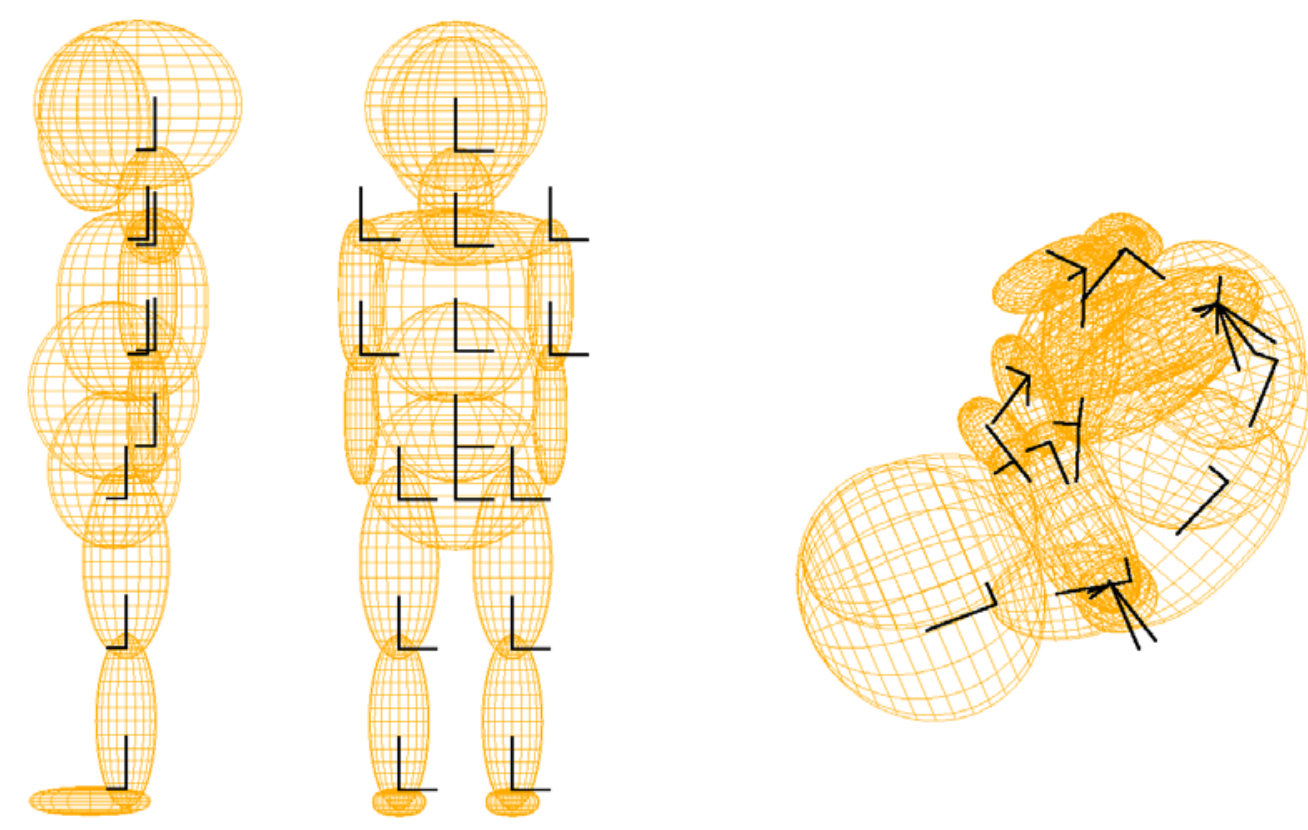

Figure 2 Left: lateral and frontal view of the fetus model showing the ellipsoid surfaces with their body local coordinate systems. Right: Lateral view of fetus model in fetal position.

\subsection{Joint Properties}

The pelvis forms the base of the model with its local coordinate system being the reference coordinate system of the model. The origin of the pelvis is located at the hip joint centre in the sagittal plane. The spine of the fetus model is divided into four joints: lumbar, thoracic, and lower and upper cervical. Spherical joints are used together with Cardan restraints consisting of three torsional parallel springs and dampers. The torques are dependent on the Bryant angles that describe the relative orientation between the two relative restraint coordinate systems. There are no translational degrees of freedom between the joints. The joint properties for the spinal joints are scaled from adult values found in the literature [28]. The hip, ankle and shoulder joints are described using spherical joints permitting three rotational degrees of freedom while the 
knee and elbow joints are represented by revolute joints allowing one degree of freedom in the physical plane of rotation. Joint restraints are used to limit the range of motion of each anatomical joint within the physiological range of motion allowed for each joint for each degree of freedom. This resistance is modelled as a sharp linear increase in stiffness past the maximum allowed free range of motion in each direction.

\subsection{Contacts}

Due to the position the fetus takes within the uterus during pregnancy, it is expected that during an impact situation there will be a large degree of interaction between body regions. It was therefore important to model body to body contact between the various anatomical surfaces. A force-penetration characteristic is defined for each ellipsoid surface that is capable of coming into contact with another region of the body. The force-penetration characteristics for the various body regions of the fetus model are determined, based on the values used in the TNO dummy models, as actual values for these material characteristics are not available in the literature, and are shown in Figure 3. It follows that the head and pelvis are the stiffest sections of the fetus due to the large skeletal bones in these areas while the abdomen is the softest. The damping and friction coefficients of 30 and 0.3 respectively as used in the TNO child dummies are used in the fetus model for all body to body contacts. The effect of the amniotic fluid is simulated by Cardan restraint element [29], which consists of three torsional parallel springs and dampers. It is used to connect the pelvis of the pregnant female and pelvis of the fetus. 


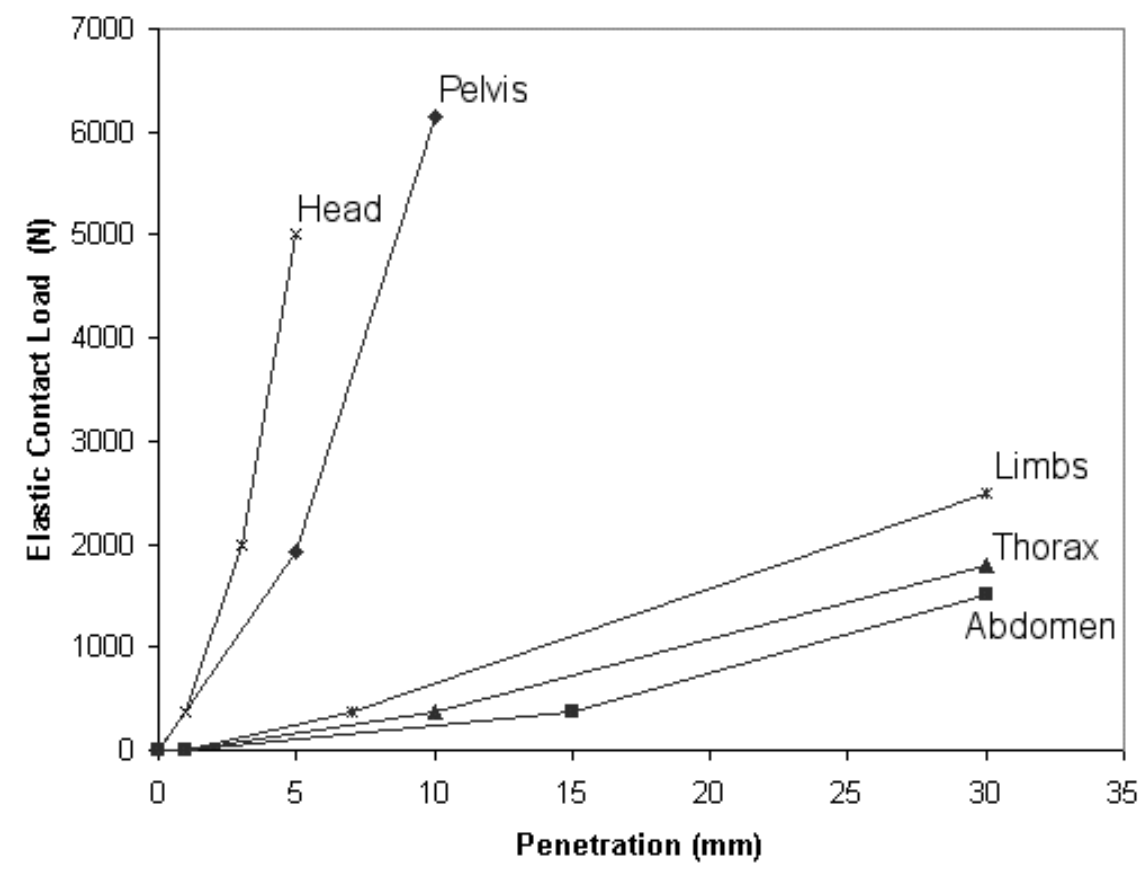

Figure 3 Force-penetration contact characteristics for the various body regions of the multibody fetus model.

\section{THE ENVIRONMENT OF THE FETUS: 'EXPECTING'}

Physical or computational models of the human body are usually validated against experimental tests on cadavers or live human volunteers. Typically, abdominal response of dummies are based on, or validated against forcedeflection data collected from dynamic testing of cadavers. In the case of human fetus, due to ethical issues, there is no force deflection data based on cadaver or volunteer tests. This means that the fetus model cannot be validated in isolation in the sense that other models are validated, but the pregnant occupant model containing the fetus model could be subjected to rigid bar impact and belt loading tests for validation. 
The detailed multibody fetus model is integrated into a finite element uterus model, which is later integrated into a female human model of MADYMO. The resultant pregnant woman model carrying a multibody fetus model is named 'Expecting'.

Generating the uterus and placenta; incorporating the 'bump' into the female model and validation of 'Expecting' are described in detail in [30]. Brief descriptions of the uterus, placenta and 'Expecting' are included in this section for completion.

\subsection{Finite Element Uterus and Placenta Model}

The finite element uterus model was developed in conjunction with the multibody fetus model with the fetal dimensions and configuration controlling the dimensions of the uterus based on data reported in [31]. This also provides a snug fit around the fetus. The material properties for the three components of the uterus model, namely the fat layer, uterus and placenta are similar to earlier

FE uterus models without the fetus. For example, the uterine wall thickness is taken as $10 \mathrm{~mm}$ [17]. Further $10 \mathrm{~mm}$ of fat layer was meshed around the outer surface of the uterus. The placenta is generated as a discoid with a diameter of $185 \mathrm{~mm}$ and thickness of $20 \mathrm{~mm}$ at its centre which is gradually reduced to $4 \mathrm{~mm}$ at the edges [16]. Two elements are used through the thickness of the uterine wall, fat layer and placenta. 

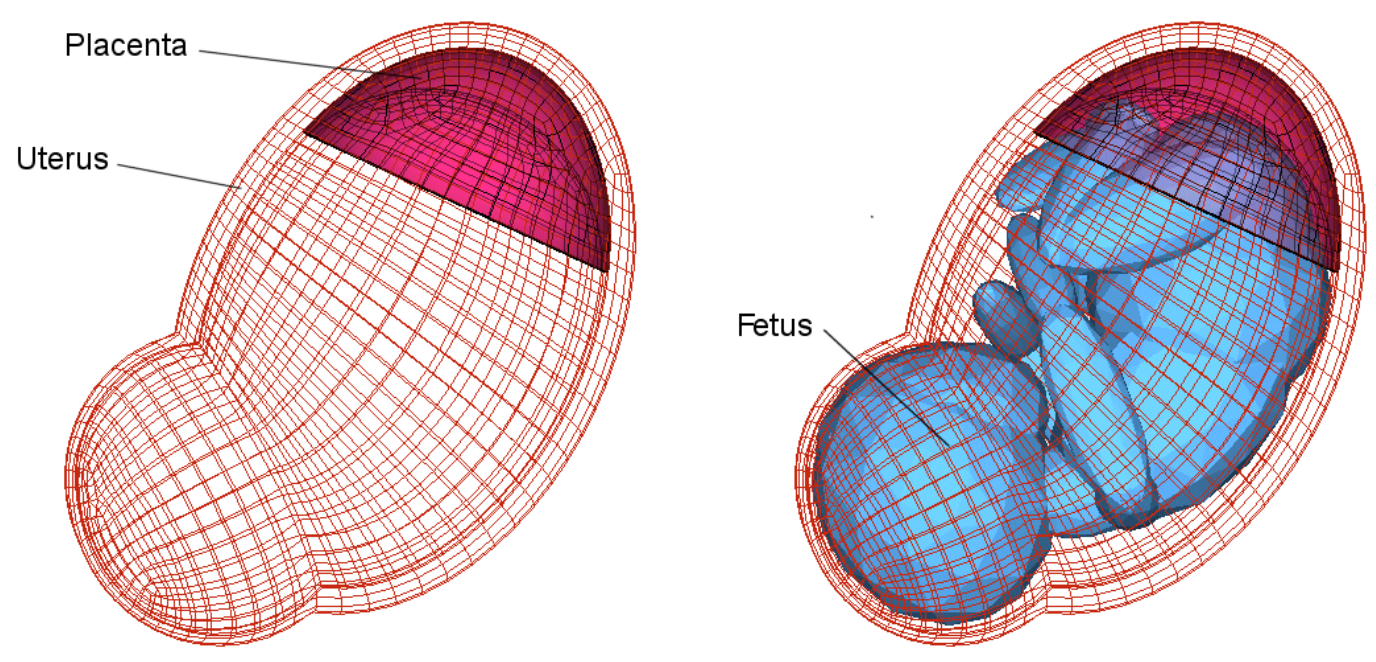

Figure 4 Side view of the FE uterus and placenta with and without the multibody fetus in position.

The uterus and placenta were meshed using Hypermesh (Altair) by first meshing the inner surface of the uterus using quad elements then mapping the elements to the outer surface to create the uterus, and mapping the corresponding elements of the placental outer surface to the inner surface of the placenta to create the placental elements. The nodal coordinates and element configuration was then exported into MADYMO where the first order 8 noded (3-D hexahedral) solid elements were used for FE components.

\section{2 'Expecting' model}

The multibody fetus, model of an unborn occupant and its environment were integrated into an existing multibody female model to complete the pregnant occupant model. The facet occupant model available within the MADYMO package represents a $5^{\text {th }}$ percentile female, $1.52 \mathrm{~m}$ in height and $49.8 \mathrm{~kg}$ in weight. The $5^{\text {th }}$ percentile model was altered to represent the anatomy of a pregnant $5^{\text {th }}$ percentile female using the anthropometric data collected from 
female volunteers in their final trimester of pregnancy [31]. The outer nodes of the portion of the FE uterus that nestles within the pelvis bones are fixed relative to the pelvis body of the human model. The remainder of the uterus is reasonably free to move, its motion being restricted only by the contact relationships with the lumbar vertebrae and the skin surface of the MADYMO human model. The resultant pregnant woman model carrying a multibody fetus model is named 'Expecting'.

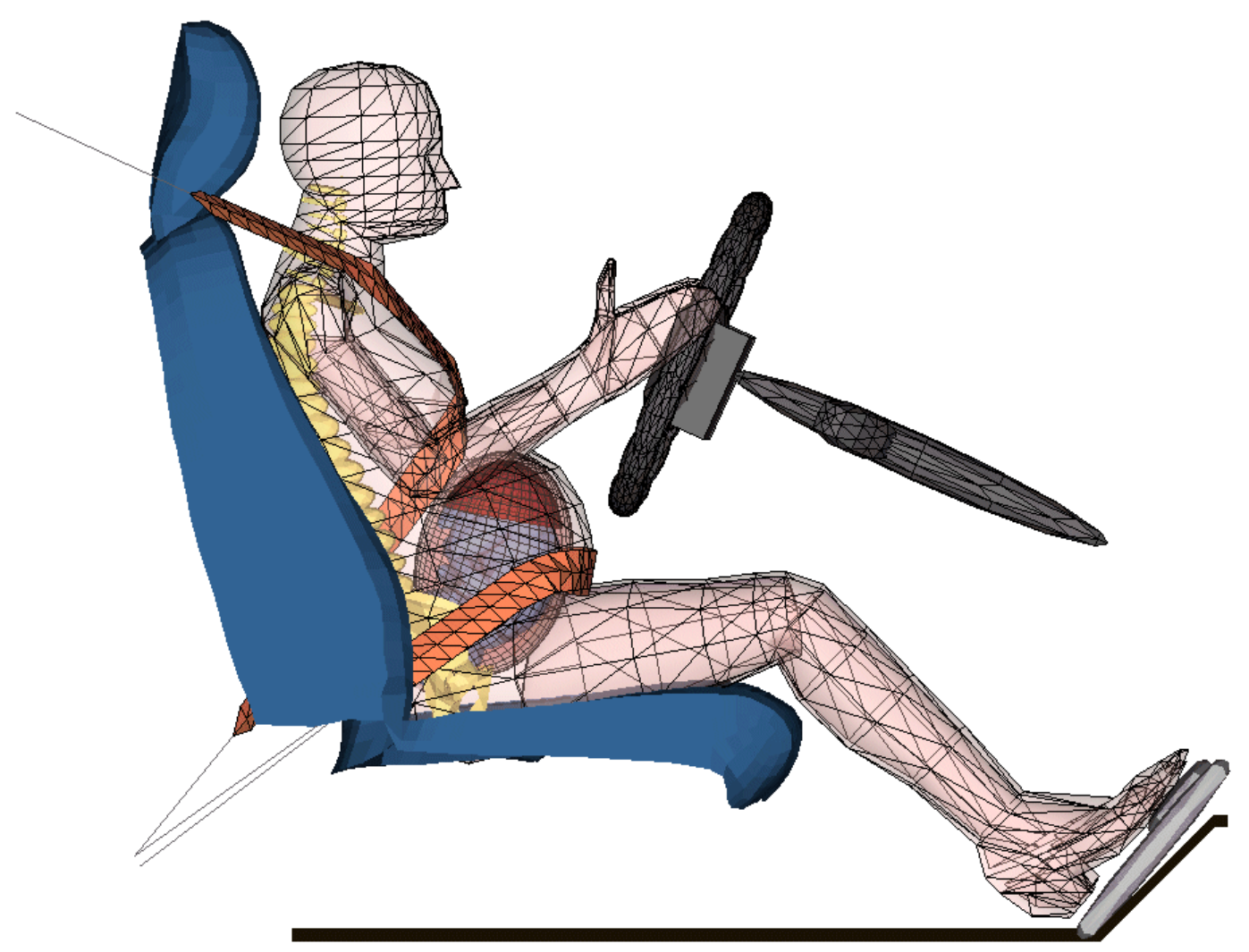

Figure 5. $38^{\text {th }}$ week pregnant female occupant model 'Expecting' in vehicle interior from Acar and Van Lopik [30].

Rigid bar impact and belt loading tests were performed by earlier researchers and the force-deflection abdominal corridors were developed for the $50^{\text {th }}$ 
percentile male [32]. As no other data is available these corridors are scaled and used in the development and validation of the 5th percentile pregnant female physical and computational models, including 'Expecting'. The comparison of a number of crash simulations and predictions by using 'Expecting' and earlier pregnant woman models are reported in [30]. Various other scenarios are simulated to investigate the fetus and pregnant woman's safety in [33-36]. Simulations and analysis indicate that taking unborn occupant into consideration is much more realistic modelling. For example, Figure 6 demonstrates the von Mises stress distribution in the uterus at $60 \mathrm{~ms}$ of a frontal crash with $\Delta v=25 \mathrm{kph}$. Pregnant occupant is restrained by a three-point seatbelt, the fetus continues to move forwards due to inertia and is forced against the anterior wall of the uterus, causing stress concentration points from loading of the head, shoulder and pelvic regions. Further observations of these movements and calculation of strains at the utero-placental interface can suggest placental abruption based on an accepted strain thresholds.

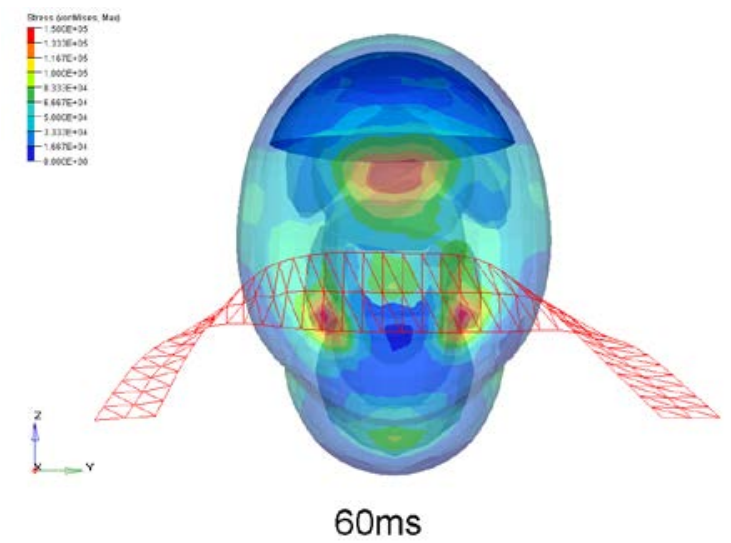

Fig 6 Frontal view of fetus and uterus demonstrating stress concentration points from loading of the head, shoulder and pelvic of the fetus at $60 \mathrm{~ms}$ of $\Delta v=25 \mathrm{kph}$ 3-point belt test. 


\section{DISCUSSION}

Earlier physical and computational models of pregnant woman in her third trimester do not carry a fetus in them. The fetus fills the uterus almost completely towards the end of pregnancy. It is considerably solid, has approximately $3.3 \mathrm{~kg}$ of mass and is relatively free to move within the uterus. It is essential to include a fetus model within a uterus model for a realistic pregnant woman model. Placental abruption is the main cause of fetal mortality in road traffic accidents and it can be predicted by the strains at the uteroplacental interface and it is the only quantifiable injury criterion for the fetus. Even if the fetus itself does not physically impact the placenta and directly cause placental abruption during an impact, its existence alone has the potential to affect the dynamic response of the pregnant occupant and the strain levels at the utero-placental interface.

'Expecting' is the only known pregnant occupant model in the world which incorporates a detailed fetus model. In this article, generating a multibody model of a fetus is explained in detail for the first time. The authors acknowledge the fact that the unborn occupant model cannot be validated in the traditional sense. However, 'Expecting' is used in predicting fetus safety in real-life accidents case studies and full agreement is achieved between the predicted and accident outcomes.

The fetus model presents an opportunity to predict fetal movements as opposed to 'no fetal movements' in earlier pregnant woman models. During an accident, inertial effects on the fetus cause it to move forwards relative to the pregnant occupant as the restraint systems restrict the expectant mother's motions. The 
fetus model provides an opportunity to observe the stress concentration points.

There is a very good indication that the unborn occupant model truly represents an unborn occupant within the model of an expectant mother. Despite the limitations, the first multibody fetus model is generated and reported here starts the life for future generation of research on unborn occupant modelling.

\section{REFERENCES}

1. Weiss HB., The epidemiology of traumatic injury-related fetal mortality in Pennsylvania, 1995-1997: The role of motor vehicle crashes. Accid. Anal. Prev., 2001, Vol. 33, 449-54.

2. Birth Statistics - Review of the Registrar General on births and patterns of family building in England and Wales, Office For National Statistics, Series FM1 No. 35, Office for National Statistics, 2007.

3. Births in Scotland - High Level Summary of Statistics Trend, GROS Registration Data, The Scottish Government, Statistics, http://www.scotland.gov.uk/Topics/Statistics/Browse/PopulationMigration/TrendBirths, October 2007.

4. Statistics Press Notice - Births in Northern Ireland, NISRA, March 2007.

5. Acar B.S. and Acar M., EPSRC Follow on Fund Final Report Development of an Improved Seat Belt Design with Particular Emphasis on the Needs of Pregnant Women (EP/E502768/1)

6. Pepperell, r.J., Rubenstein, E. and Maclsaac, I.A., Motor-car accidents during pregnancy. Medical Journal of Australia, 1977, Vol. 1, 203-5.

7. Bunai, Y., Nagai, A., Nakamura, I. And Ohya, I., Fetal death from abruptio placentae associated with incorrect use of a seatbelt. American Journal of Forensic Medicine and Pathology, 2000, Vol. 21, 3, 207-9.

8. Crosby, W.M. and Costiloe, J.P., Safety of lap-belt restraint for pregnant victims of automobile collisions. New England Journal of Medicine, Vol. 284, 632-636.

9. Agran, P.F., Dunkle, D.E., Winn, D.G. and Kent, D., Fetal death in motor vehicle accidents. Annals of Emergency Medicine, 1987, Vol. 16, 12, 135558

10.Goodwin, T.M. and Breen, M.T., Pregnancy outcome and fetomaternal hemorrhage after noncatastrophic trauma. American Journal of Obstetrics \& 
Gynecology, 1990, Vol. 162, 3, 665-71.

11.Pearlman, M.D., Tintinalli, J.E. and Lorenz, R.P, A prospective controlled study of outcome after trauma during pregnancy. American Journal of Obstetrics \& Gynecology, 1990, Vol. 126, 6, 1501-10.

12.King A.I, Crosby W.M., Stout L.C., Eppinger R.H., Effects of lap belt and three-point restraints on pregnant baboons subjected to deceleration. Proceedings of the 15th Stapp Car Crash Conference; 1971 Nov 17-19; San Diego, California Society of Automotive Engineers, (1971) p. 83.

13.Pearlman M. D. and Viano D, Automobile Crash Simulation with the first pregnant crash test dummy, Am J Obstet Gynecol, 1996, 175: 977-981.

14.Rupp, J.D., Schneider, L.W., Klinich, K.D., Moss, S., Zhou, J., and Pearlman, M.D. Design, development, and testing of a new pregnant abdomen for the Hybrid III small female crash test dummy. UMTRI-2001-07, 2001.

15. Moorcroft, D., Duma, S., Stitzel, J., and Duma, G. A finite element and multibody model of the pregnant female occupant for the analysis of restraint effectiveness. SAE 2003-01-0157,

16. Gray's Anatomy $39^{\text {th }}$ Ed., Standing, S., Editor-in-chief, Elsevier Churchhill Livingstone.

17. England, M.A., A colour atlas of life before birth - Normal Fetal Development, 1983, Wolfe Medical Publications Ltd.

18. Acar BS, Weekes AM. Design Guidelines for Pregnant Occupant Safety. Journal of Automobile Engineering (Journal of IMechE Part D), 2005, 219(7), pp. 857-867.

19.Snijders, R.J.M., and Nicolaides, K.H. Fetal biometry at 14-40 weeks gestation. Ultrasound Obstet. Gynec., 1994, 4(1), 34-48.

20. Hadlock F.P.,Deter R.L.,Harrist R.D.,Park S.K. Fetal biparietal diameter: a critical re-evaluation of the relation to menstrual age by means of real-time ultrasound. J Ultrasound Med 1982; 1:97-104.

21.Pheasant S. Bodyspace. Anthropometry, Ergonomics and Design, 1988. Taylor \& Francis, London.

22. Jeanty $\mathrm{P}$, Rodesch $\mathrm{F}$, Delbeke D, Dumont JE Estimation of gestational age from measurements of fetal long bones. J Ultrasound Med. 1984 Feb;3(2):75-9.

23. Chervenak F A, McCullough LB, Wapner RJ. Selective termination to a singleton pregnancy is ethically justified. Ultrasound Obstet Gynecol. 1992 Mar 1;2(2):84-7 
24. British Standards Institution, Body Measurements of boys and girls from birth up to 16.9 years. Information in the form of tables, 7231-1:1990, London.

25. Romero R, Pilu G, Jeanty P, Ghidini A, Hobbins J (Eds) Prenatal Diagnosis of congenital anomalies, 1983, pp323-324, Appleton and Lange, East Norwalk, Connecticut.

26. Yeadon M R and Morlock M The appropriate use of regression equations for the estimation of segmental inertia parameters, Journal of Biomechanics, 1989, 22(6-7), 683-9.

27.Chandler, R. F., Clauser, C. E., McConville, J. T., Reynolds, H. M. and Young, J. W. Investigation of inertial properties of the human body. AMRL Technical Report 1975, 74-137, Wright-Patterson Air Force Base, OH.

28. Prasad P. and King A. I. An experimentally validated dynamic model of the spine J Appl Mech 41:545-550, 1974.

29. MADYMO HUMAN MODELS MANUAL. Facet Occupant Models. TNO Automotive, 2005, 221-53.

30. Acar, B.S. and Van Lopik D. Pregnant Occupant Model 'Expecting' for Crash Simulations, Journal of Automobile Engineering (Journal of IMechE, Part D), 2009, 223(7): 891-902 .

31.Acar, B.S., and Weekes, A.M. Measurements for pregnant driver comfort and safety. International Journal of Vehicle Design, 2006 42(1), 101-118.

32. Hardy, W.N., Schneider, L.W., and Rouhana, S.W. Abdominal impact response to rigid-bar, seatbelt, and airbag loading. Stapp Car Crash J., 2001, 45, 1-32.

33. Acar, B.S. and Esat $V$ Pregnant driver injury investigations through modelling and simulation of full-frontal crashes with and without airbags International Journal of Human Factors Modelling and Simulation 2011, 2(1):3-13

34. Acar, B.S. and Esat V A Computational Investigation on Seat Belt Use for Pregnant Drivers in Airbag Equipped Automobiles, Proceedings of 10th Biennial Engineering Systems Design and Analysis (American Society of Mechanical Engineers) Conference, 2010, 1-6.

35. Weekes A, Acar BS Testing to Investigate the Use of Lap Belt Positioners During Pregnancy Proceedings of 10th Biennial Engineering Systems Design and Analysis (American Society of Mechanical Engineers) Conference Jul 2010, 1-15. 
36. Esat $V$ and Acar, B.S. Pregnant Driver Injury Investigations in Oblique Crashes, International Journal of Crashworthiness, to appear in 2012. 